\title{
Miniplacas permitem tratamento eficiente e eficaz da mordida aberta anterior
}

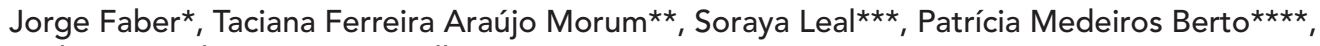

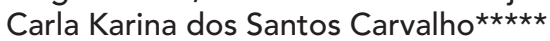

\section{Resumo}

Introdução: o tratamento das deformidades e más oclusões que incluem mordidas abertas anteriores foi uma das primeiras aplicações de miniplacas como forma de ancoragem ortodôntica. A implementação desse sistema de tratamento reduz o número de pacientes indicados para a cirurgia ortognática e simplifica muitos problemas. Nessa abordagem, os dentes posteriores são intruídos e a mandíbula sofre um giro no sentido anti-horário, diminuindo a altura facial inferior e projetando os pogônios de tecidos duro e mole. Objetivo: o presente artigo apresenta os fundamentos da mecânica ortodôntica para correção da mordida aberta anterior e os ilustra com uma série de casos clínicos.

Palavras-chave: Mordida aberta. Procedimentos de ancoragem ortodôntica. Miniplacas. Ortodontia.

\section{INTRODUÇÃO}

Uma terapia ortodôntica bem sucedida depende do planejamento criterioso da ancoragem. O recurso de ancoragem esquelética representou um grande avanço que se consolidou na Ortodontia ${ }^{10}$. Ele é caracterizado pela obtenção de um ponto fixo e imóvel de ancoragem dentro da cavidade bucal, o que facilita a movimentação ortodôntica, pois evita o deslocamento da unidade de resistência. Os implantes ortodônticos temporários são técnicas de ancoragem esquelética que apresentam vantagens em relação à Ortodontia tradicional em muitas situações clínicas, pois não dependem da colaboração do paciente e permitem a aplicação de força em diversas direções, sem a presença de movimentos recíprocos indesejáveis ${ }^{15}$.
$\mathrm{O}$ advento da ancoragem esquelética tem permitido que profissionais tracem novos caminhos para o tratamento ortodôntico. Tratamentos complexos tornaram-se mais simples e previsíveis, a duração dos tratamentos diminuiu e cirurgias ortognáticas puderam ser evitadas em pacientes que não desejavam se submeter a elas.

Esses resultados foram atingidos com vários sistemas de ancoragem esquelética diferentes. $\mathrm{O}$ processo natural de seleção das técnicas restringiu os sistemas de ancoragem a, praticamente, dois grupos: mini-implantes e miniplacas ${ }^{24}$. O uso de miniplacas como ancoragem ortodôntica foi concebido, inicialmente, para distalização de molares inferiores ${ }^{21}$. Entretanto, ganhou popularidade apenas a partir da demonstração de sua aplicabilidade

\footnotetext{
* Editor-chefe da Revista Dental Press de Ortodontia e Ortopedia Facial. Doutor em Biologia pelo Laboratório de Microscopia Eletrônica da UnB. Mestre em Ortodontia pela UFRJ.

** Especialista em Ortodontia pela FOPLAC. Mestranda em Ciências da Saúde pela Universidade de Brasília.

*** Especialista em Odontopediatria pela ABO-DF. Mestre e Doutora em Ciências da Saúde pela UnB. Professora Adjunto da Universidade de Brasília. **** Pós-graduanda em Ortodontia - UFG.

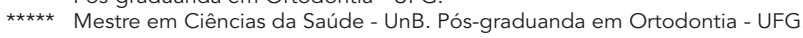


no tratamento da mordida aberta anterior por meio da intrusão de molares ${ }^{24}$.

As miniplacas têm suas vantagens calcadas na sua maior estabilidade e no fato de os mini-implantes de fixação estarem além do nível dos ápices dentários, possibilitando a movimentação dos dentes adjacentes ao implante no sentido ânteroposterior, vertical ${ }^{10}$ e transversal. Elas são mais indicadas em situações que necessitam da aplicação de forças ortodônticas mais intensas ou movimentos de vários dentes ${ }^{3,22}$. Como não interferem nos movimentos dentários, também é permitido transladar dentes na área da miniplaca ${ }^{6,10,12,21}$. Adicionalmente, as miniplacas não demandam outra colaboração dos pacientes, além da higienização e manutenção da integridade do aparelho ${ }^{10}$. Elas também são estáveis para resistir a forças ortodônticas nos vários movimentos dentários e apresentam altos índices de sucesso ${ }^{7,24}$.

As miniplacas apresentam algumas desvantagens, quando comparadas aos mini-implantes, tal como requerer cirurgias de instalação e remoção mais invasivas, ter custos mais altos e apresentar, possivelmente, maior probabilidade de infecção ${ }^{7,15,14}$.

Entretanto, há situações clínicas onde elas são vantajosas, e as maiores indicações para esse sistema são a intrusão, a distalização e a mesialização de todos os dentes maxilares ou mandibulares, ainda que ofereçam ancoragem esquelética adequada para vários outros tipos de movimentos dentários ${ }^{12,18,23}$.

Várias são as aplicações clínicas desses dispositivos de ancoragem. Uma indicação comum é no tratamento de mordidas abertas anteriores. Grande parte dos adultos com mordida aberta anterior apresenta excesso dentoalveolar posterior da maxila. Nesses pacientes, geralmente, indicava-se a realização de cirurgia ortognática para impacção da porção posterior da maxila e conseqüente rotação da mandíbula no sentido anti-horário. Atualmente, existem opções de tratamento menos invasivas, como a instalação de miniplacas para a intrusão de molares. Essa intrusão será responsável por alterações no plano oclusal, plano mandibular e porção anterior da face, que fecharão a mordida aberta anterior ${ }^{10,11,19,20}$.

A intrusão de todos os dentes posteriores para correção da mordida aberta anterior pode ser atingida com sucesso e previsibilidade com esse dispositivo, e o objetivo desse artigo é apresentar uma metodologia de tratamento da mordida aberta anterior com a utilização de miniplacas como ancoragem esquelética.

\section{INSTALAÇÃO DAS MINIPLACAS}

Dentre os fatores que influenciam o sucesso dos dispositivos de ancoragem esquelética, consideram-se como importantes a qualidade e a quantidade de osso cortical do sítio de implantação e as características da mucosa ao redor. Miniplacas cujas emergências na cavidade bucal são cercadas de mucosa ceratinizada têm, estatisticamente, mais chances de sucesso que aquelas localizadas em mucosa alveolar, onde existe maior probabilidade de infecção ${ }^{1,8}$.

A influência da localização anatômica para dispositivos de ancoragem também é considerada importante. Mas, em relação a esse assunto, existem divergências entre autores. Enquanto Kuroda et al. ${ }^{15}$ consideram que implantes localizados na região posterior da mandíbula estão mais propensos à falha, em relação àqueles posicionados na região posterior da maxila, Chen et al. ${ }^{1}$ consideram que aqueles implantados na maxila, geralmente, apresentam menor estabilidade que aqueles implantados na mandíbula. Entretanto, ainda que o osso maxilar seja mais poroso e a cortical mais delgada, sendo plausível haver menor índice de sucesso na maxila que na mandíbula ${ }^{17}$, nossa experiência com mais de 400 miniplacas instaladas mostra que não há, na verdade, diferença na estabilidade. Já as razões do fato descrito por Kuroda et al. ${ }^{15}$ permanecem obscuras, mas algumas possibilidades são especuladas, como a menor quantidade de gengiva ceratinizada, maior dificuldade de higiene e maior 
dificuldade cirúrgica, devido à conformação anatômica da mandíbula ${ }^{16}$.

O planejamento de miniplacas só deve ser realizado após a análise detalhada da documentação ortodôntica do paciente, determinação do plano de tratamento e biomecânica a ser utilizada. Antes da cirurgia, deve-se avaliar cuidadosamente o local eleito para instalação do implante, de acordo com a qualidade do osso, analisando-se a radiografia panorâmica ou a tomografia.

Além disso, um guia cirúrgico deve ser confeccionado para orientar o posicionamento ideal das miniplacas, sendo esse recurso de grande valia para se evitar lesões em estruturas anatômicas ${ }^{10,21}$.

A escolha do tamanho e do formato da miniplaca é baseada no comprimento das raízes dos dentes adjacentes e no contorno e densidade do osso subjacente. Miniplacas em formato de "L" são mais indicadas para a mandíbula, pois a perna mais curta projeta-se anteriormente, facilitando o acesso. Enquanto, na maxila, placas em forma de "Y" ou de "T" são mais usadas, pois são mais facilmente contornadas ao redor do osso maxilar, nas regiões onde há osso cortical, evitando-se essas placas sobre o osso do seio maxilar ${ }^{19}$.

O local de instalação da miniplaca é selecionado de acordo com a viabilidade do osso, biomecânica utilizada e integridade do tecido mole adjacente ${ }^{3}$. As miniplacas são, normalmente, instaladas no processo zigomático da maxila ou no corpo da mandíbula. O processo zigomático da maxila representa um sítio adequado na maxila, pois apresenta uma estrutura óssea sólida e está localizado a uma distância segura das raízes dos molares superiores ${ }^{8}$.

A cirurgia de instalação da miniplaca é feita sob anestesia local. Inicialmente, usava-se uma incisão sulcular horizontal como método cirúrgico. Atualmente, esta é substituída, em certos casos, por uma incisão vertical, para simplificar a operação cirúrgica, reduzir o tamanho da cicatriz e facilitar a cicatrização ${ }^{9}$. Após a dissecção do tecido e exposição óssea, a miniplaca é ajustada ao contor- no ósseo e fixada com dois ou três mini-implantes. O tecido é fechado e suturado, permitindo a exposição de um elo para dentro da cavidade bucal.

O pós-operatório da instalação de miniplacas é caracterizado por edema e dor mínimos ${ }^{8}$. Cuidados especiais de higiene devem ser realizados após a instalação das miniplacas. Recomenda-se a utilização de escova pós-cirúrgica embebida em gluconato de clorexidina $0,12 \%$ durante 15 dias e utilização de anti-séptico à base de triclosan durante todo o período de tratamento.

Em relação ao tempo de espera para aplicação de força ortodôntica, existe a possibilidade de força imediata após a instalação, mas é mais recomendável esperar, pelo menos, 2 semanas $^{23,24}$, para conforto do paciente em relação à cicatrização dos tecidos moles.

\section{COMPLICAÇÕES COM O USO DE MINIPLACAS}

O uso de miniplacas como ancoragem ortodôntica também pode ter algumas complicações. Uma das mais comuns é a inflamação e/ou infecção ao redor da miniplaca, devido à acumulação de placa bacteriana por falta de higiene do paciente $^{9,21}$. Quando a infecção não é resolvida com irrigação e higienização do local e antibioticoterapia, deve-se remover a miniplaca. Entretanto, raramente isso é necessário. As inflamações são, em geral, facilmente controladas pelo uso de anti-sépticos bucais e escovação adequada ${ }^{1}$. O biofilme formado sobre mini-implantes, se tratado com clorexidina ou solução de fluoreto, sofre diminuição significativa de microrganismos viáveis. Mas a adesividade das bactérias também é influenciada pela superfície do substrato, como presença de rugosidades e composição química superficial ${ }^{4}$.

Outra complicação - incomum - associada às miniplacas é a irritação da mucosa jugal pelo dispositivo de ancoragem esquelética. Essa característica provoca certo desconforto ao paciente, mas, geralmente, não interfere no índice de sucesso das 
miniplacas ${ }^{9}$. Um fator importante, que pode levar a falhas na ancoragem ortodôntica, é a proximidade dos mini-implantes às raízes dentárias, pois essa proximidade dificulta a remodelação óssea ao redor do mini-implante e permite a transmissão de força oclusal dos dentes aos mini-implantes ${ }^{16}$. Mas as miniplacas são posicionadas, em geral, afastadas das raízes dentárias e dificilmente os miniimplantes que sustentam a placa tocam a lâmina dura ao redor das raízes dentárias.

Outro fator que poderia estar associado ao risco de perda de sistemas de ancoragem esquelética é a alta força de tração, mas é difícil definir claramente essa influência. Quando se tentou associar diferentes tipos de força (elástico de corrente, mola de níquel-titânio ou elástico de corrente associado a mola) aos índices de insucesso de miniplacas, não foi possível identificar essa associação².

\section{BIOMECÂNICA DA CORREÇÃO DA MORDI- DA ABERTA ANTERIOR COM MINIPLACAS}

A força vertical intrusiva é gerada por elástico de corrente ou mola de níquel-titânio presa ao elo exposto da placa e ao tubo do molar (Fig. 1).
Pode-se usar tanto arcos segmentados como contínuos (Fig. 2A). Ainda que já se tenha sugerido que o emprego de arcos contínuos pudesse acarretar uma sobre-irrupção dos incisivos, devido a um giro no plano oclusal ${ }^{19}$, nossa experiência clínica mostra que esse efeito não ocorre (Fig. 2B) e já publicamos um exemplo desse fato ${ }^{11}$.

Para evitar a vestibularização dos molares durante a aplicação de força intrusiva, indica-se o uso de arco retangular constrito ou, mais freqüentemente, barra transpalatina ou arco lingual (Fig. 3). Eventuais alterações indesejáveis no plano transversal podem ser solucionadas com a colagem de um tubo diretamente na miniplaca e o uso de um braço de força ativado no sentido da correção (Fig. 4) 9,10,19,20.

A intrusão de molares em apenas um dos maxilares é efetiva para correção de mordidas abertas de até $3 \mathrm{~mm}^{10}$. Mordidas abertas mais significativas devem ser corrigidas com miniplacas nos dois arcos. A intrusão simultânea dos molares superiores e inferiores permite maior rotação da mandíbula no sentido anti-horário e mudanças esqueléticas mais significativas ${ }^{14}$.

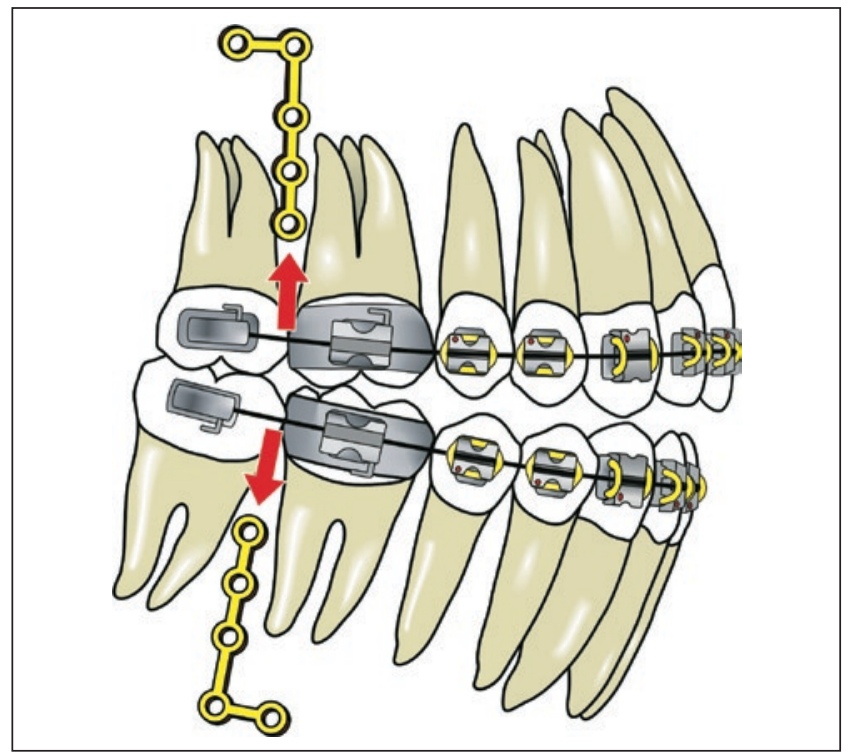

FIGURA 1 - Esquema que representa a força intrusiva aplicada do elo mais oclusal da miniplaca ao aparelho. 

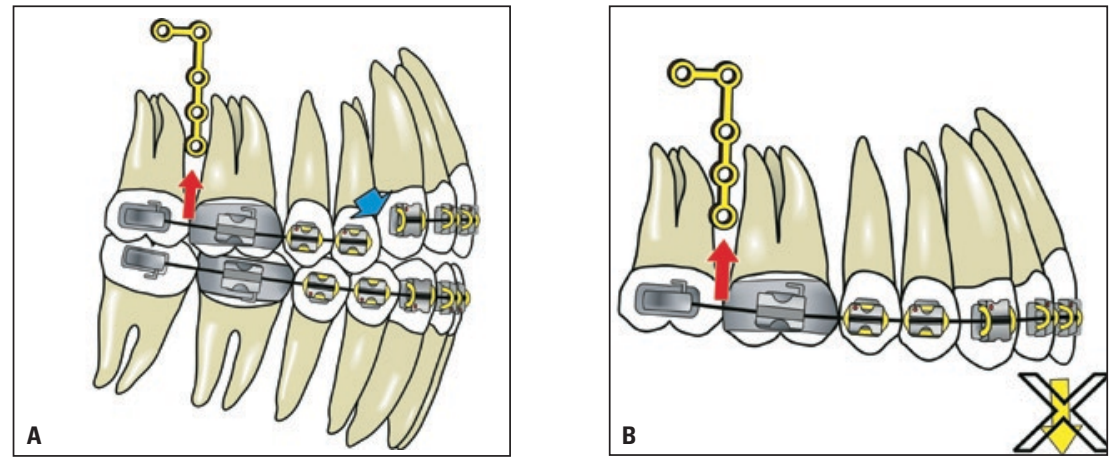

FIGURA 2 - Questões mecânicas relacionadas à intrusão. A) Tanto arcos contínuos quanto segmentados podem ser empregados. Os segmentados (seta azul) têm especial vantagem em casos onde a mordida aberta é circunscrita à região anterior. B) Quando arcos contínuos são utilizados, não ocorre extrusão dos incisivos (X sobre a seta amarela), como já foi sugerido ${ }^{18}$, mas não demonstrado na literatura.

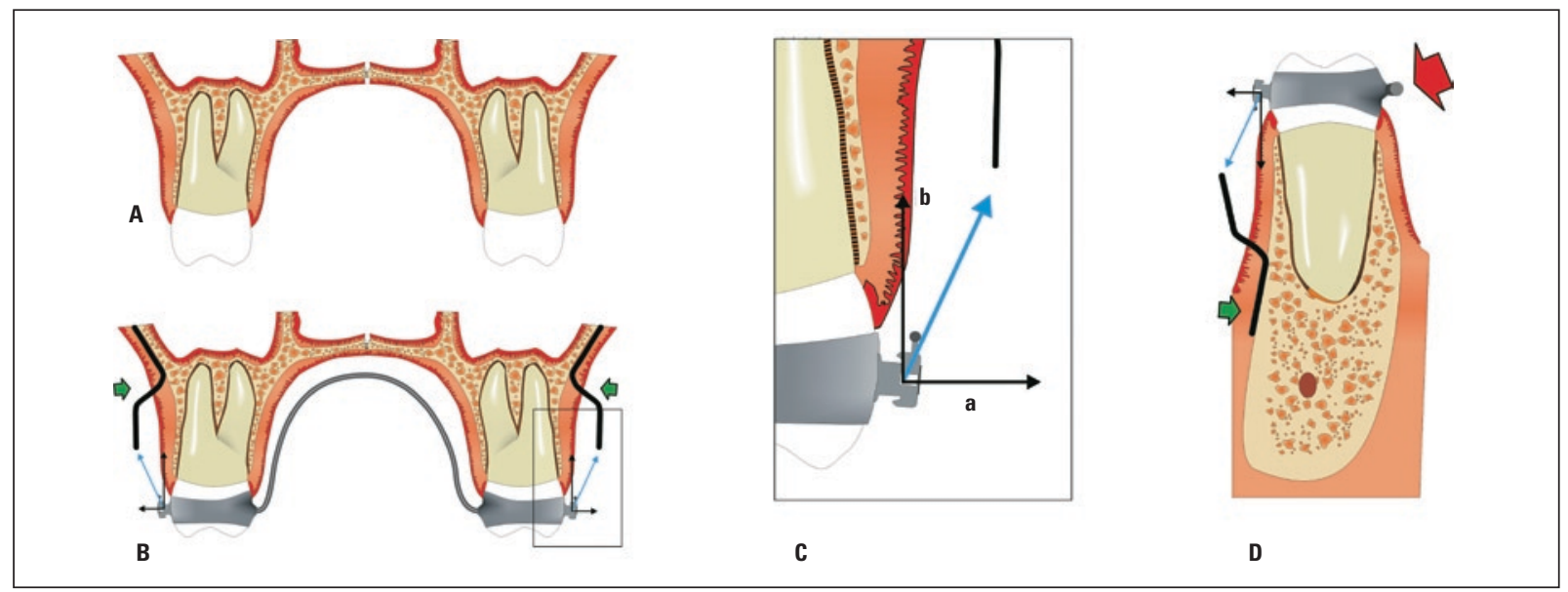

FIGURA 3 - Esquemas que representam cortes transversais da maxila na região do $1^{\circ}$ molar superior. A) Antes da montagem do aparelho. B) Instalação das miniplacas (setas verdes) e aplicação das forças de intrusão (setas azuis). C) As forças intrusivas decompostas em possuem componente expansivo (a) e intrusivo (b). Os componentes expansivos se anulam na presença de uma barra palatina ou (D) arco lingual (seta vermelha).

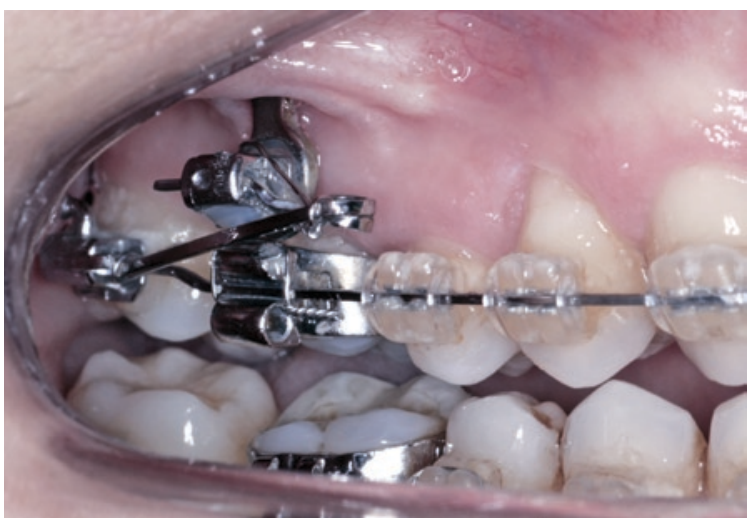

FIGURA 4 - Para corrigir eventuais alterações transversais nos arcos superior e inferior, um braquete ou tubo pode ser colado diretamente à placa e ser usado para ancorar arcos, molas e outros dispositivos. Para tanto, duas pequenas ranhuras devem ser feitas dentro do elo da placa, para reter a resina da colagem. 


\section{CASOS CLÍNICOS}

\section{Caso 1 - miniplacas em maxila e mandíbula unilateralmente}

Paciente do gênero masculino, com 21 anos e 9 meses de idade, apresentava uma má oclusão de Classe I com mordida aberta severa, na qual apenas segundos molares do lado direito ocluíam, e uma assimetria vertical caracterizada por inclinação da maxila e abaixamento desta no lado direito (Fig. 5). Radiografias da ATM e cintilografia foram solicitadas para avaliar a possível hipercaptação do côndilo esquerdo. A análise desses exames descartou a existência de possíveis alterações morfológicas nos côndilos e hiperplasia ou neoplasia condilares, respectivamente (Fig. 6).

\section{Objetivos do tratamento}

O objetivo do tratamento foi o fechamento da mordida aberta e a obtenção de sobremordida e sobressaliência adequadas.

\section{Alternativas de tratamento}

As seguintes alternativas de tratamento foram apresentadas ao paciente:

1. Tratamento ortodôntico associado à cirurgia ortognática combinada na maxila e na mandíbula.

2. Tratamento ortodôntico com a implantação de duas miniplacas de titânio no lado direito, uma na maxila e outra na mandíbula.

\section{Progresso do tratamento}

Após o alinhamento e o nivelamento dos dentes inferiores e superiores, guias cirúrgicos foram fabricados para orientar o cirurgião quanto ao posicionamento desejado para as miniplacas. Antes da realização da cirurgia, uma barra palatina e um arco lingual foram instalados, com o propósito de impedir a vestibularização dos dentes posteriores durante o processo de intrusão. Esses aparelhos tiveram seus fios destemperados do lado esquerdo, para obter-se maior flexibilidade e permitir a
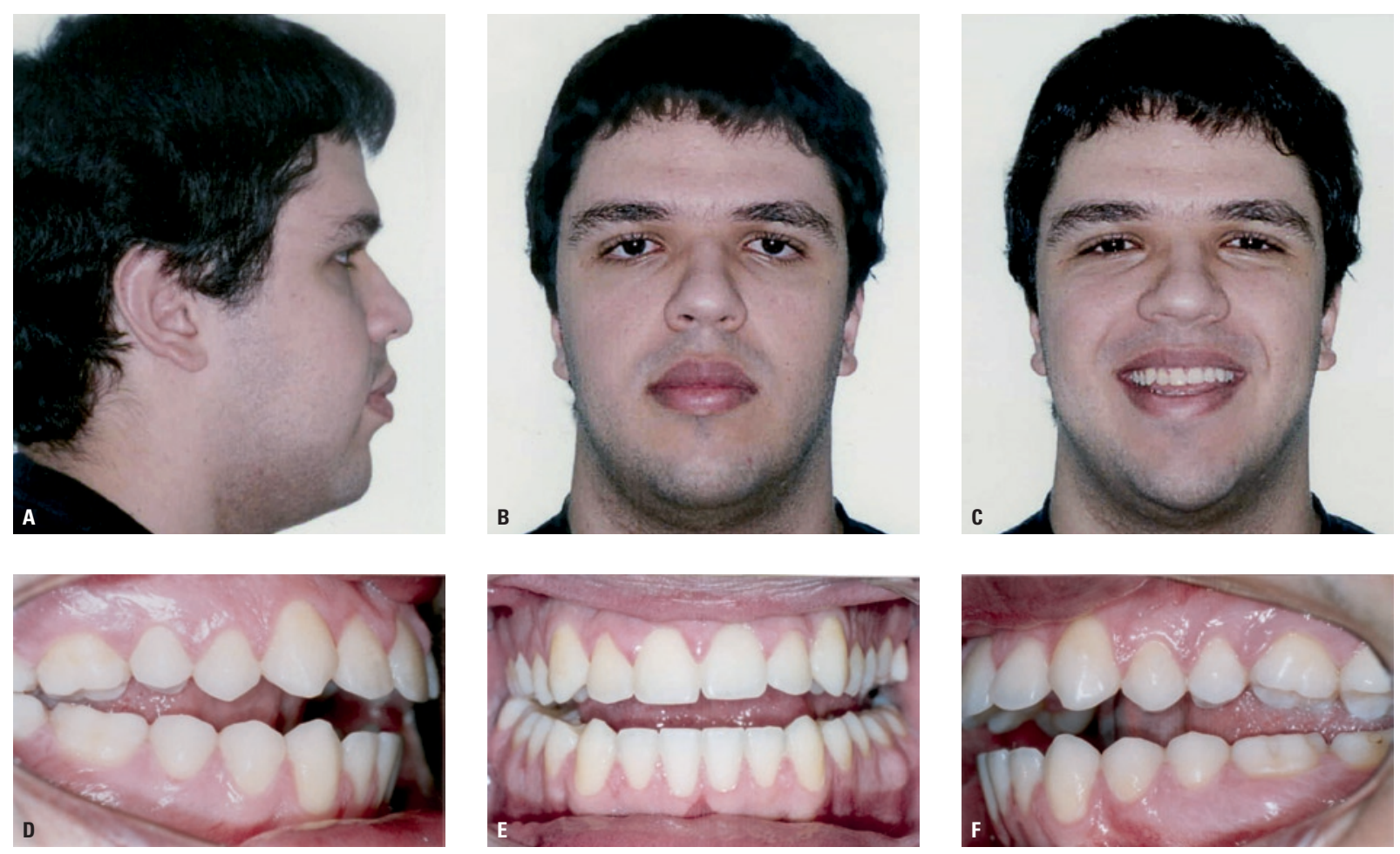

FIGURA 5 - Fotos iniciais apresentando mordida aberta assimétrica: A, B, C) imagens extrabucais e D, E, F) imagens intrabucais. 

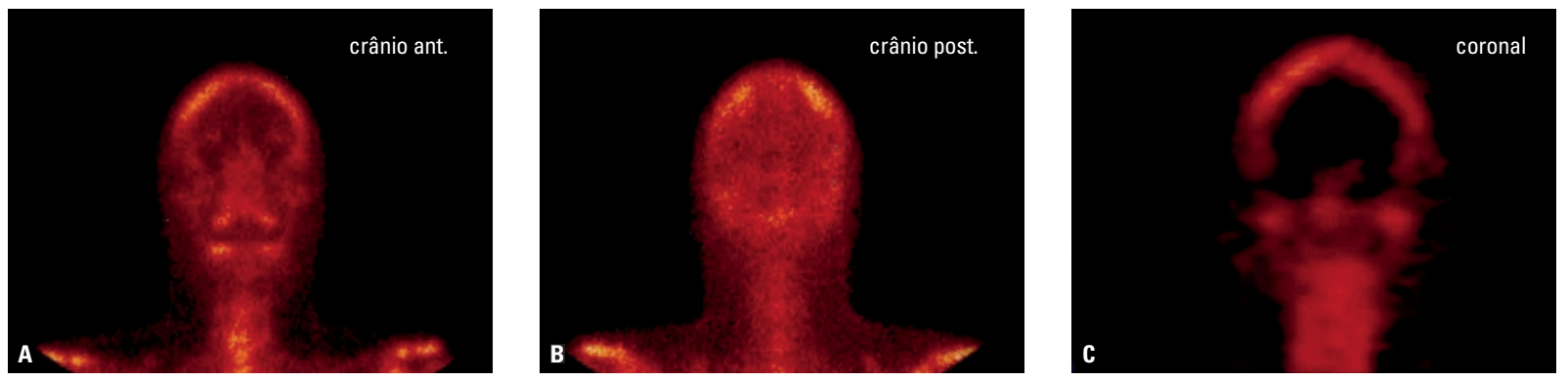

FIGURA 6 - Imagens da cintilografia: A) corte anterior, B) corte posterior e C) corte coronal.
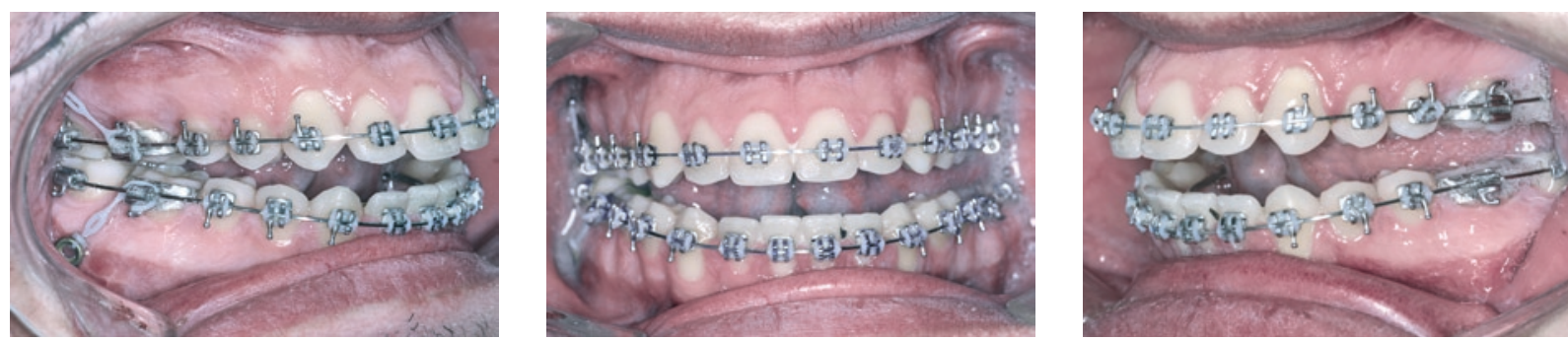

FIGURA 7 - Evolução do tratamento com a implementação de elásticos em corrente, das miniplacas para os primeiros molares direitos, a fim de intruir os dentes posteriores.
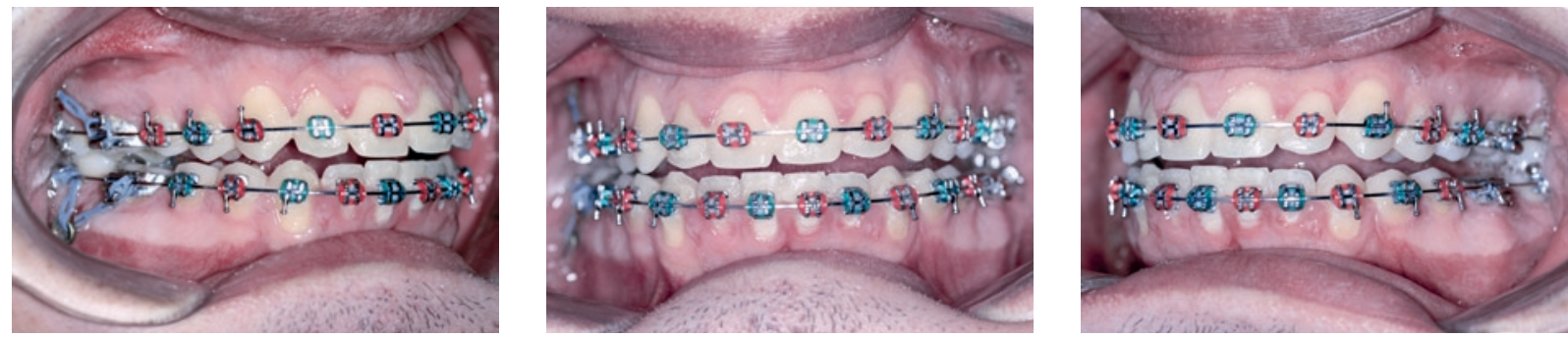

FIGURA 8 - Progresso da intrusão dos molares e conseqüente fechamento da mordida aberta, onde os elásticos em corrente foram estendidos, também, para os segundos molares.

movimentação adequada.

Duas semanas após a implantação das miniplacas no lado direito da mandíbula e maxila, foram inseridos elásticos em corrente, desde as miniplacas até os primeiros molares, a fim de intruir os dentes posteriores (Fig. 7). Na seqüência, os elásticos para intrusão foram estendidos, também, para os segundos molares (Fig. 8). Assim que uma sobremordida adequada foi atingida, iniciou-se um tratamento fonoaudiológico que perdurou durante todo o período do tratamento ortodôntico.

\section{Resultados}

Os molares superiores e inferiores direitos fo-

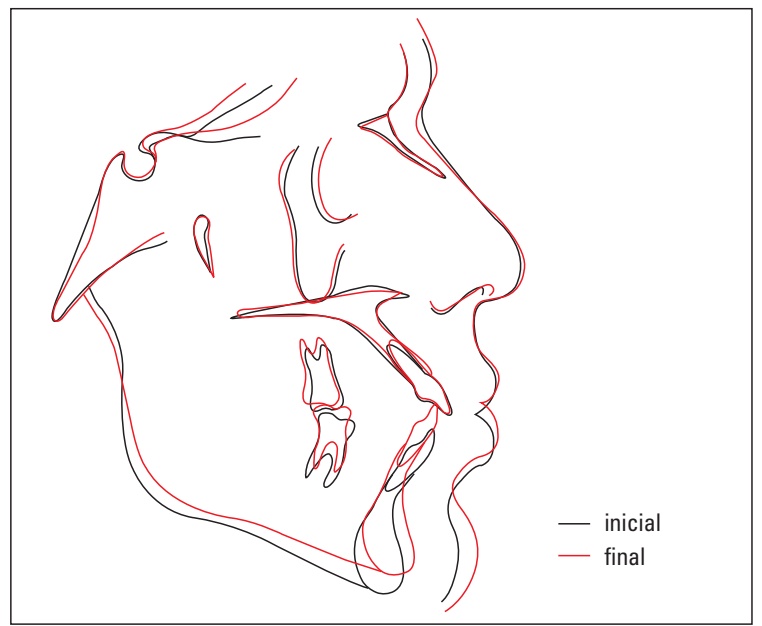

FIGURA 9 - Traçados cefalométricos inicial e final sobrepostos, mostrando a intrusão dos molares superiores e inferiores direitos e conseqüente giro da mandíbula no sentido anti-horário. 

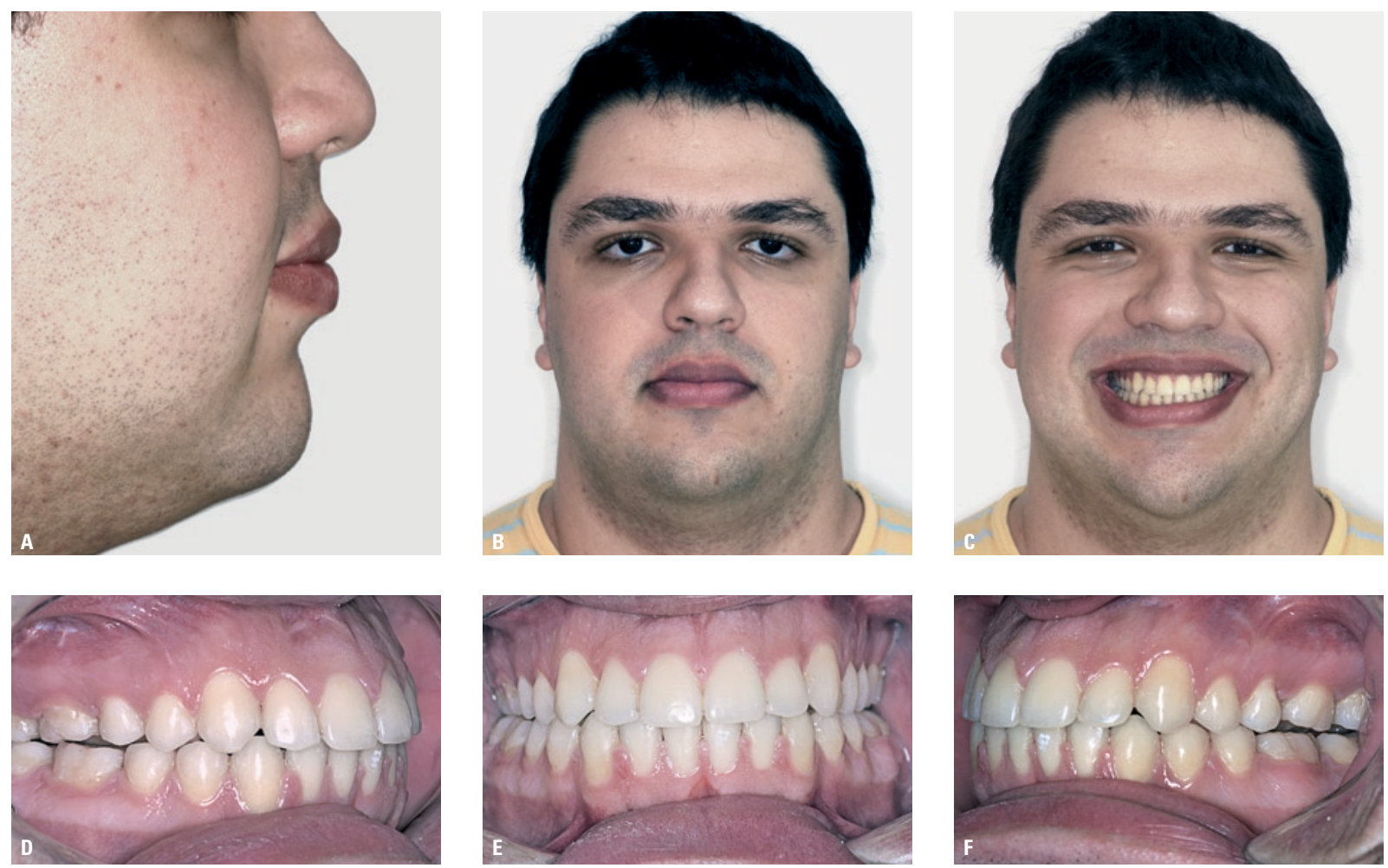

FIGURA 10 - Fotografias finais com as adequadas relações dentárias estabelecidas: A, B, C) imagens extrabucais e D, E, F) imagens intrabucais.

Tabela 1 - Medidas cefalométricas iniciais e finais (caso 1).

\begin{tabular}{|cccc|}
\hline medidas & norma & inicial & final \\
\hline SNA & $82^{\circ}$ & $74^{\circ}$ & $76^{\circ}$ \\
\hline SNB & $80^{\circ}$ & $79^{\circ}$ & $81^{\circ}$ \\
\hline ANB & $2^{\circ}$ & $-4^{\circ}$ & $-5^{\circ}$ \\
\hline 1/. NA & $22^{\circ}$ & $47^{\circ}$ & $38^{\circ}$ \\
\hline 1/-NA & $4 \mathrm{~mm}$ & $23 \mathrm{~mm}$ & $22 \mathrm{~mm}$ \\
\hline /1.NB & $25^{\circ}$ & $39^{\circ}$ & $33^{\circ}$ \\
\hline /1-NB & $4 \mathrm{~mm}$ & $12 \mathrm{~mm}$ & $10,5 \mathrm{~mm}$ \\
\hline /1.1/ & $131^{\circ}$ & $98^{\circ}$ & $114^{\circ}$ \\
\hline NB-Pog & & $3 \mathrm{~mm}$ & $3 \mathrm{~mm}$ \\
\hline SN.Poi & & $19^{\circ}$ & $11^{\circ}$ \\
\hline SN.Pos & & $15^{\circ}$ & $14^{\circ}$ \\
\hline SN.GoGn & $32^{\circ}$ & $31^{\circ}$ & $29^{\circ}$ \\
\hline AFAl & & $95 \mathrm{~mm}$ & $91 \mathrm{~mm}$ \\
\hline g-sn & & $68 \mathrm{~mm}$ & $70 \mathrm{~mm}$ \\
\hline sn-stms & & $34 \mathrm{~mm}$ & $34 \mathrm{~mm}$ \\
\hline stmi-me & & $68 \mathrm{~mm}$ & $68 \mathrm{~mm}$ \\
\hline stms-stmi & & $0 \mathrm{~mm}$ & $0 \mathrm{~mm}$ \\
\hline
\end{tabular}

* g = glabela; sn = subnasal; stms = estômio superior; stmi = estômio inferior; $\mathrm{me}=$ mento em tecido mole. ram intruídos e a mandíbula sofreu um giro antihorário (Fig. 9). A tabela 1 apresenta as medidas cefalométricas iniciais e finais, com diminuição da altura facial inferior. Ao final do tratamento ortodôntico, foram estabelecidas boas relações dentárias (Fig. 10). A contenção inferior empregada foi uma barra $3 \times 3$. Adicionalmente, para o arco superior, foram feitas duas contenções removíveis tipo wraparound: uma convencional, para uso diurno, e outra com grade palatina na região lateral direita, para uso noturno. Decorridos seis meses do fim do tratamento ortodôntico, apenas a contenção noturna continuou a ser utilizada.

\section{Caso 2 - miniplacas em mandíbula bilateralmente}

Paciente do gênero feminino, com 30 anos de idade, compareceu para consulta apresentando uma relação ântero-posterior adequada, porém com uma mordida aberta anterior que a incomodava (Fig. 11). Não existiam apinhamentos im- 

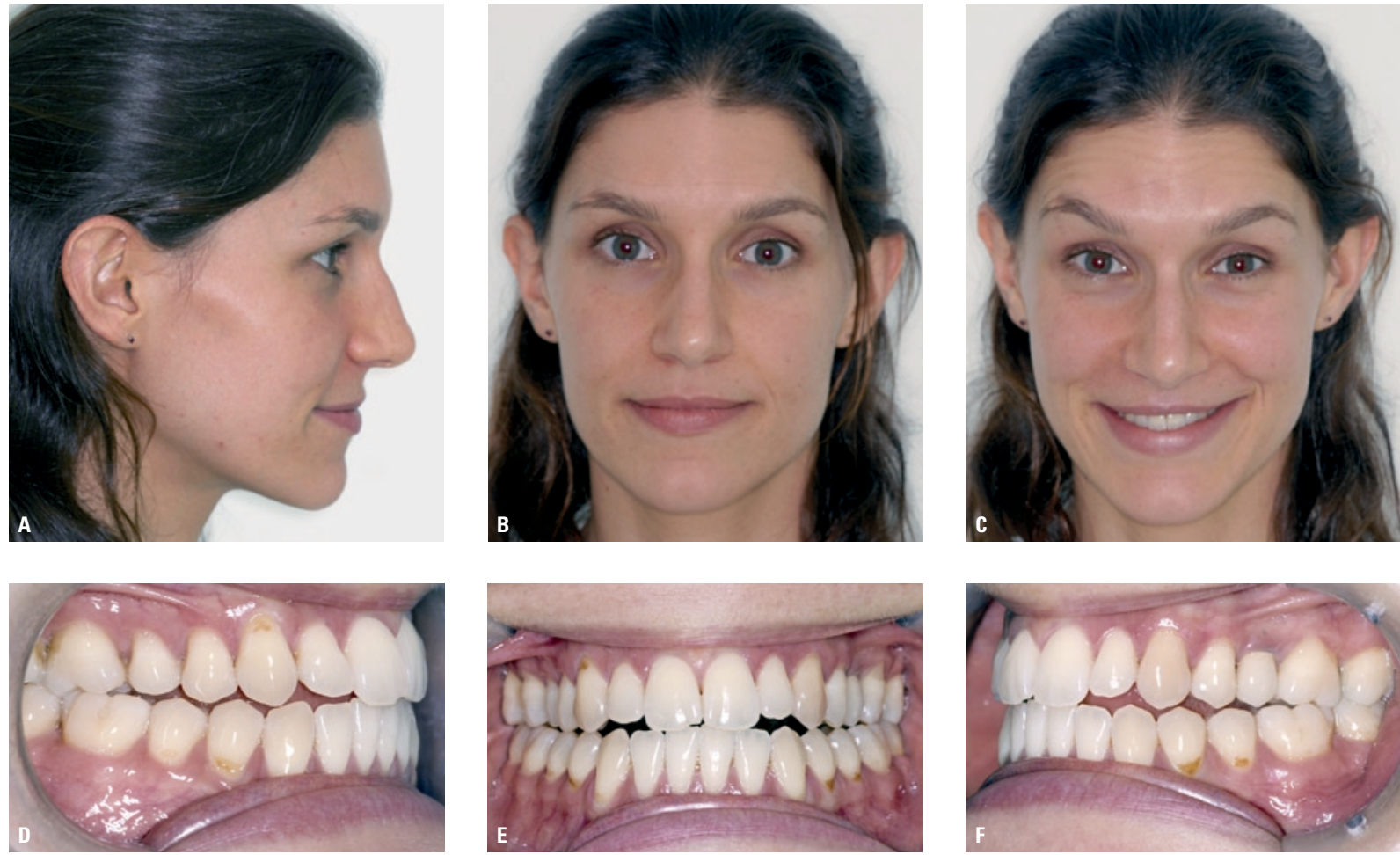

FIGURA 11 - Fotos iniciais extrabucais (A, B, C) e intrabucais (D, E, F) apresentando mordida aberta anterior.
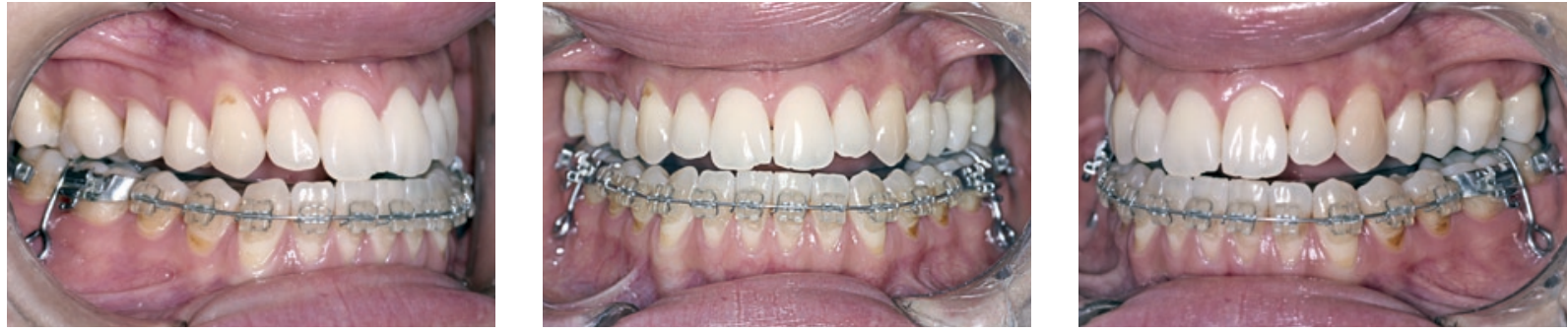

FIGURA 12 - Imagens intrabucais com o guia cirúrgico posicionado no arco inferior.
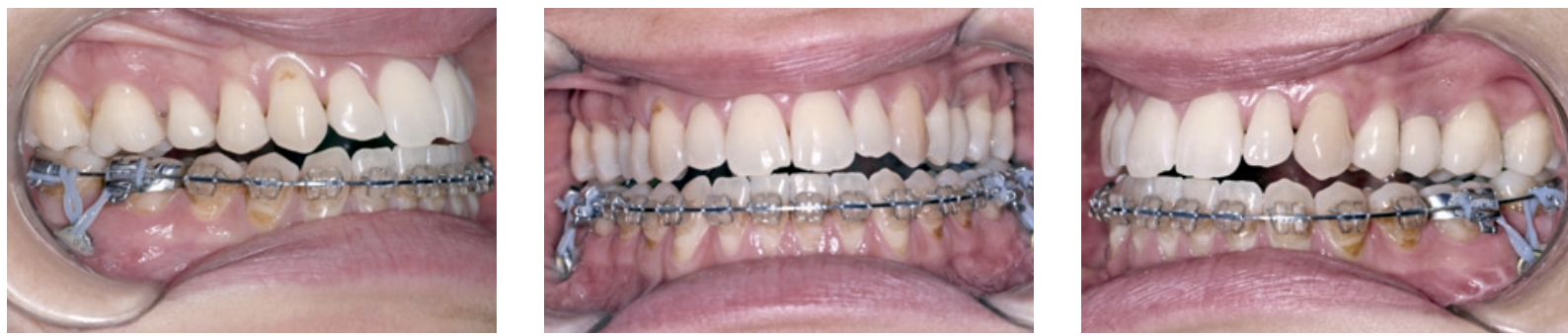

FIGURA 13 - Evolução do tratamento com a ativação do aparelho utilizando elásticos em corrente apoiados nas miniplacas para intrusão dos molares inferiores. 
portantes nos arcos superior e inferior. A paciente apresentava um implante osteointegrado na região do dente 25, que impactou de forma importante no planejamento da ancoragem esquelética.

\section{Objetivos do tratamento}

O objetivo do tratamento foi a obtenção de adequadas sobremordida e sobressaliência, com a correção da mordida aberta.

\section{Alternativas de tratamento}

As seguintes alternativas de tratamento foram apresentadas à paciente, explicando-se as vantagens e desvantagens de cada uma:

1. Tratamento ortodôntico com uso de elásticos verticais anteriores, para extrusão dos incisivos e caninos.

2. Tratamento ortodôntico com a implantação de duas miniplacas de titânio na mandíbula, para intrusão dos molares. As miniplacas não foram indi- cadas para a região de maxila, devido à presença do implante osteointegrado na região do dente 25.

\section{Progresso do tratamento}

O tratamento consistiu na montagem do aparelho ortodôntico no arco inferior, incluindo a instalação de um arco lingual para se evitar a vestibularização dos dentes inferiores durante a intrusão. Três meses após o início do alinhamento e nivelamento dos dentes inferiores, confeccionou-se um guia cirúrgico que indicava ao cirurgião a posição desejada do elo mais oclusal das miniplacas (Fig. 12).

Duas semanas após a cirurgia de instalação das miniplacas, iniciou-se a mecânica de intrusão. Esse tempo de espera é apenas para se atingir um bom nível de cicatrização dos tecidos moles adjacentes e, conseqüentemente, um maior conforto da paciente durante a manipulação da região. A mecânica foi realizada por meio de elásticos em corrente, para intruir os molares (Fig. 13), contudo,
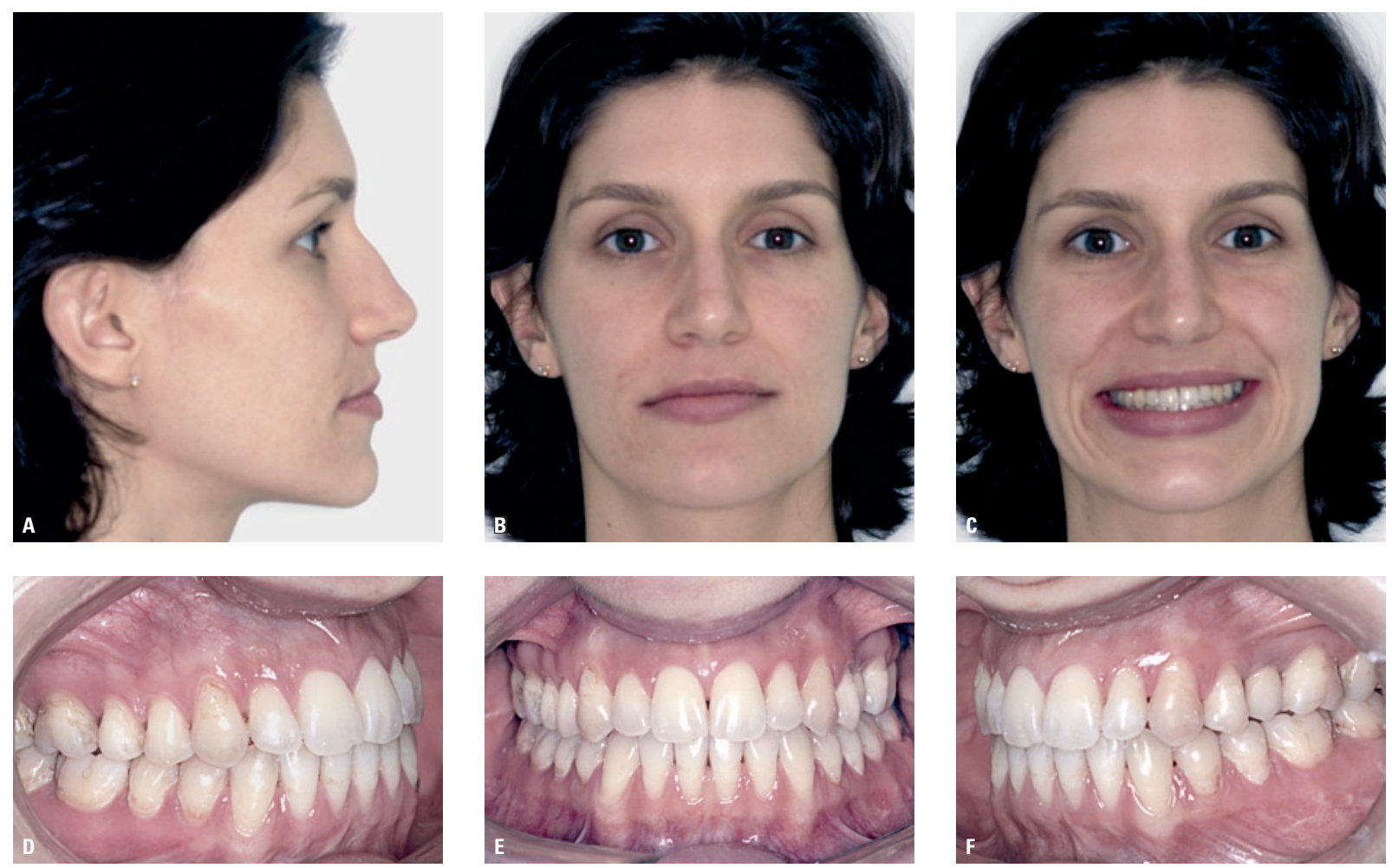

FIGURA 14 - Fotografias finais com a correta oclusão estabelecida: A, B, C) imagens extrabucais e D, E, F) imagens intrabucais. 


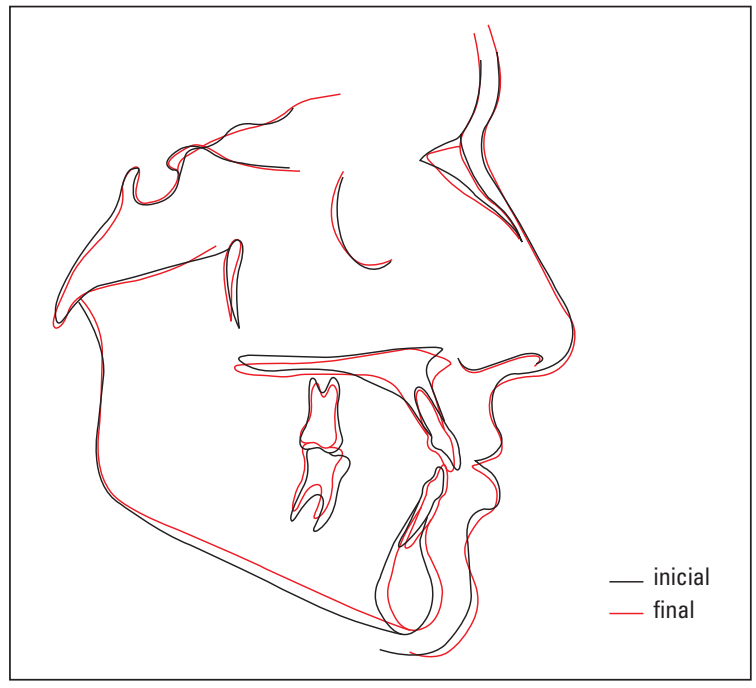

FIGURA 15 - Traçados cefalométricos inicial e final sobrepostos, mostrando a intrusão dos molares inferiores e conseqüente giro da mandíbula no sentido anti-horário.
Tabela 2 - Medidas cefalométricas iniciais e finais (caso 2).

\begin{tabular}{|cccc}
\hline medidas & norma & inicial & final \\
\hline SNA & $82^{\circ}$ & $73^{\circ}$ & $75^{\circ}$ \\
SNB & $80^{\circ}$ & $75^{\circ}$ & $76^{\circ}$ \\
\hline ANB & $2^{\circ}$ & $-2^{\circ}$ & $-1^{\circ}$ \\
\hline 1/. NA & $22^{\circ}$ & $32^{\circ}$ & $30^{\circ}$ \\
\hline 1/-NA & $4 \mathrm{~mm}$ & $10,5 \mathrm{~mm}$ & $7,5 \mathrm{~mm}$ \\
\hline /1.NB & $25^{\circ}$ & $22^{\circ}$ & $23^{\circ}$ \\
\hline /1-NB & $4 \mathrm{~mm}$ & $3,5 \mathrm{~mm}$ & $4,5 \mathrm{~mm}$ \\
\hline /1.1/ & $131^{\circ}$ & $129^{\circ}$ & $127^{\circ}$ \\
\hline NB-Pog & & $4 \mathrm{~mm}$ & $4,5 \mathrm{~mm}$ \\
\hline SN.Poi & & $17^{\circ}$ & $14^{\circ}$ \\
\hline SN.Pos & & $17^{\circ}$ & $18^{\circ}$ \\
\hline SN.GoGn & $32^{\circ}$ & $32^{\circ}$ & $32^{\circ}$ \\
\hline AFAI & & $69 \mathrm{~mm}$ & $67 \mathrm{~mm}$ \\
\hline g-sn & & $63 \mathrm{~mm}$ & $65 \mathrm{~mm}$ \\
\hline sn-stms & & $22 \mathrm{~mm}$ & $22 \mathrm{~mm}$ \\
\hline stmi-me & & $48 \mathrm{~mm}$ & $48 \mathrm{~mm}$ \\
\hline stms-stmi & & $0 \mathrm{~mm}$ & $0 \mathrm{~mm}$ \\
\hline
\end{tabular}

* $\mathrm{g}$ = glabela; sn = subnasal; stms = estômio superior; stmi = estômio inferior; $\mathrm{me}=$ mento em tecido mole.

\section{Caso 3 - miniplacas em maxila bilateralmente}

Paciente do gênero feminino, com 22 anos e 8 meses de idade, apresentava, ao exame clínico, uma má oclusão de Classe I com mordida aberta anterior.

\section{Objetivos do tratamento}

O objetivo do tratamento foi corrigir a mordida aberta anterior, proporcionando sobremordida e sobressaliência adequadas.

\section{Alternativas de tratamento}

As seguintes alternativas de tratamento foram apresentadas à paciente:

1. Tratamento ortodôntico com uso de elásticos verticais anteriores.

2. Tratamento ortodôntico com uso de ancoragem esquelética - instalação de duas miniplacas de titânio na maxila direita e esquerda. 

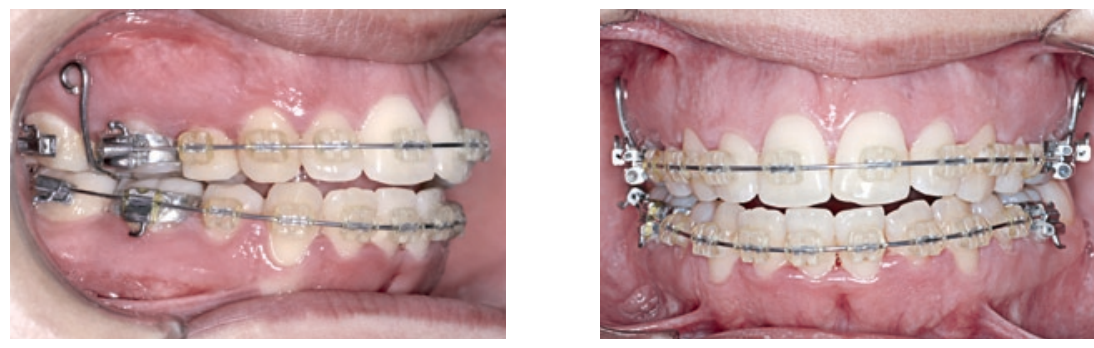

FIGURA 16 - Aparelho ortodôntico fixo montado nos arcos superior e inferior, com um guia cirúrgico posicionado no arco superior para orientar o cirurgião quanto ao posicionamento desejado para as miniplacas.
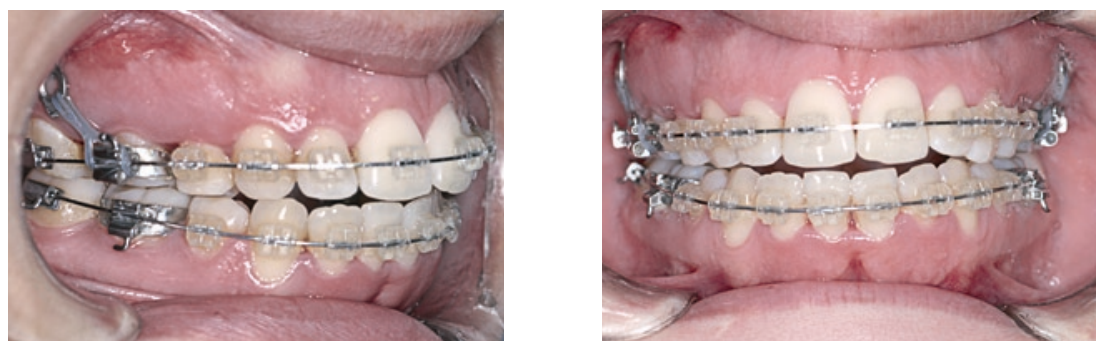

FIGURA 17 - Início do movimento de intrusão dos molares superiores por meio do uso de elásticos em corrente ancorados nas miniplacas.
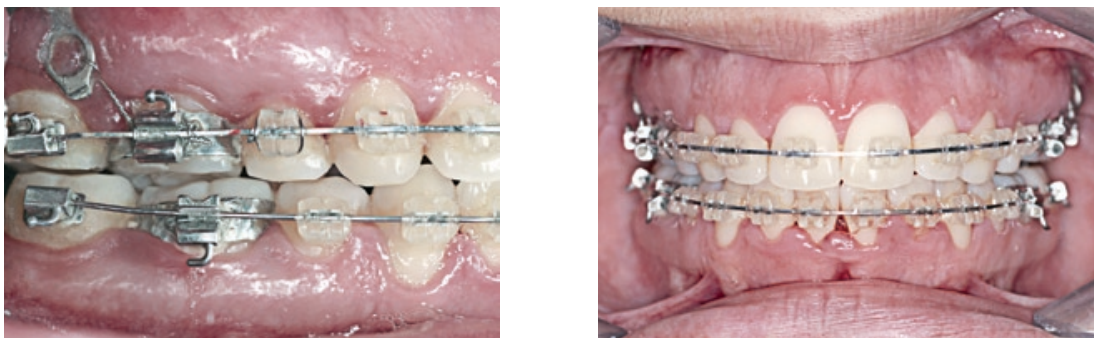

FIGURA 18 - Contenção do movimento de intrusão, com amarração em fios de aço.

\section{Progresso do tratamento}

Inicialmente, realizou-se o alinhamento e nivelamento dos dentes inferiores e superiores. Procedeu-se, então, a instalação do guia cirúrgico (Fig. 16) e de uma barra palatina para impedir a vestibularização indesejada dos dentes posteriores.

Duas semanas após a implantação das miniplacas na maxila, foram colocados arcos 0,017 " $\mathrm{x}$ 0,025" em aço e elásticos em corrente, das miniplacas aos primeiros molares superiores, para intrusão destes (Fig. 17). Assim que uma sobremordida adequada foi atingida, fez-se uma contenção da intrusão, com fios de aço das miniplacas aos molares (Fig. 18). A paciente realizou, desde esse momento, um tratamento fonoaudiológico e foi orientada quanto a necessidade de sua manutenção.

\section{Resultados}

Finalizou-se o tratamento ortodôntico com relações dentárias adequadas e correção da mordida aberta (Fig. 19). A tabela 3 apresenta as medidas cefalométricas iniciais e finais do caso. Houve uma intrusão dos molares superiores, levando a um giro anti-horário da mandíbula e, assim, a uma diminuição da altura facial inferior (Fig. 20). As contenções utilizadas foram as mesmas dos casos descritos anteriormente: barra $3 \mathrm{x}$ 3 fixa inferior e duas contenções removíveis tipo wraparound: uma convencional, para uso diurno, e outra com grade palatina, para uso noturno. Seis meses após o término do tratamento ortodôntico, apenas a contenção noturna continuou a ser utilizada. 

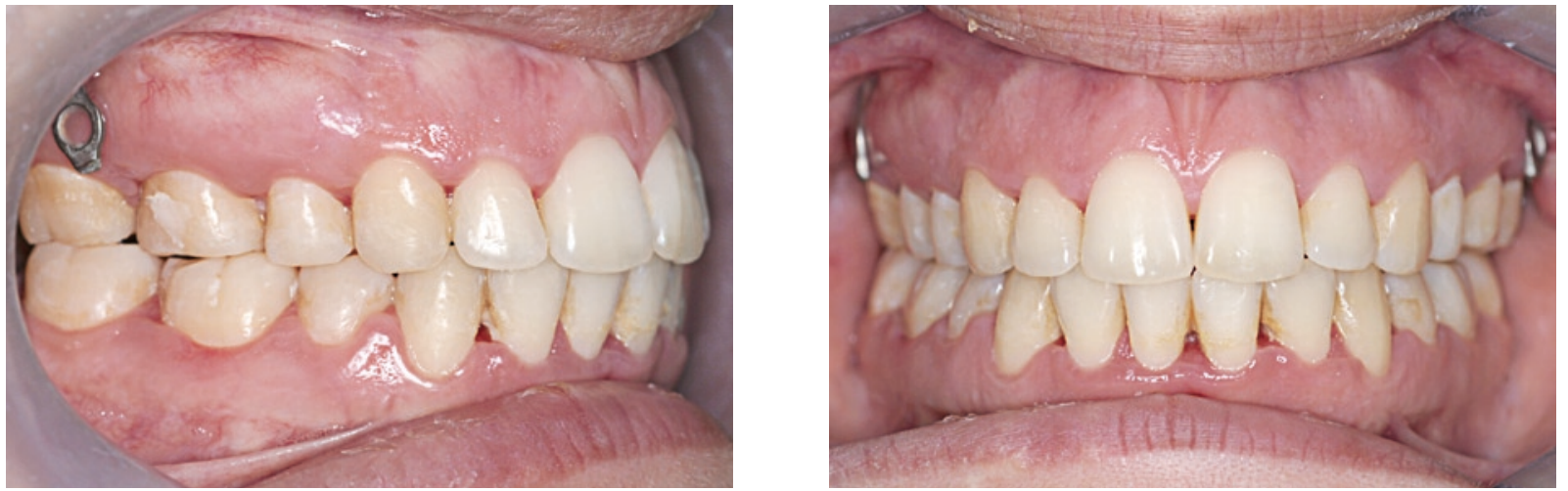

FIGURA 19 - Imagens intrabucais finais com as adequadas relações dentárias estabelecidas.

Tabela 3 - Medidas cefalométricas iniciais e finais (caso 3).

\begin{tabular}{|cccc}
\hline medidas & norma & inicial & final \\
\hline SNA & $82^{\circ}$ & $76^{\circ}$ & $74^{\circ}$ \\
\hline SNB & $80^{\circ}$ & $70^{\circ}$ & $70^{\circ}$ \\
\hline ANB & $2^{\circ}$ & $6^{\circ}$ & $4^{\circ}$ \\
\hline 1/. NA & $22^{\circ}$ & $22^{\circ}$ & $21^{\circ}$ \\
1/-NA & $4 \mathrm{~mm}$ & $8 \mathrm{~mm}$ & $8 \mathrm{~mm}$ \\
\hline /1.NB & $25^{\circ}$ & $36^{\circ}$ & $36^{\circ}$ \\
\hline /1-NB & $4 \mathrm{~mm}$ & $12,5 \mathrm{~mm}$ & $12 \mathrm{~mm}$ \\
\hline /1.1/ & $131^{\circ}$ & $115^{\circ}$ & $118^{\circ}$ \\
\hline NB-Pog & & $0,5 \mathrm{~mm}$ & $1 \mathrm{~mm}$ \\
\hline SN.Poi & & $24^{\circ}$ & $24^{\circ}$ \\
\hline SN.Pos & & $24^{\circ}$ & $27^{\circ}$ \\
\hline SN.GoGn & $32^{\circ}$ & $46^{\circ}$ & $45^{\circ}$ \\
\hline AFAl & & $87 \mathrm{~mm}$ & $84 \mathrm{~mm}$ \\
\hline g-sn & & $63 \mathrm{~mm}$ & $63 \mathrm{~mm}$ \\
\hline sn-stms & & $23 \mathrm{~mm}$ & $23 \mathrm{~mm}$ \\
\hline stmi-me & & $49 \mathrm{~mm}$ & $47 \mathrm{~mm}$ \\
\hline stms-stmi & & $13 \mathrm{~mm}$ & $10 \mathrm{~mm}$ \\
\hline
\end{tabular}

* $\mathrm{g}$ = glabela; $\mathrm{sn}$ = subnasal; stms = estômio superior; stmi = estômio inferior; $\mathrm{me}=$ mento em tecido mole.

\section{CONCLUSÕES}

As mordidas abertas anteriores podem ser tratadas, com eficácia e eficiência, por meio de miniplacas que servem de ancoragem para intrusão dos dentes posteriores, intruindo-os e acarretando um giro mandibular anti-horário, diminuindo a altura facial inferior e projetando os pogônios de tecidos

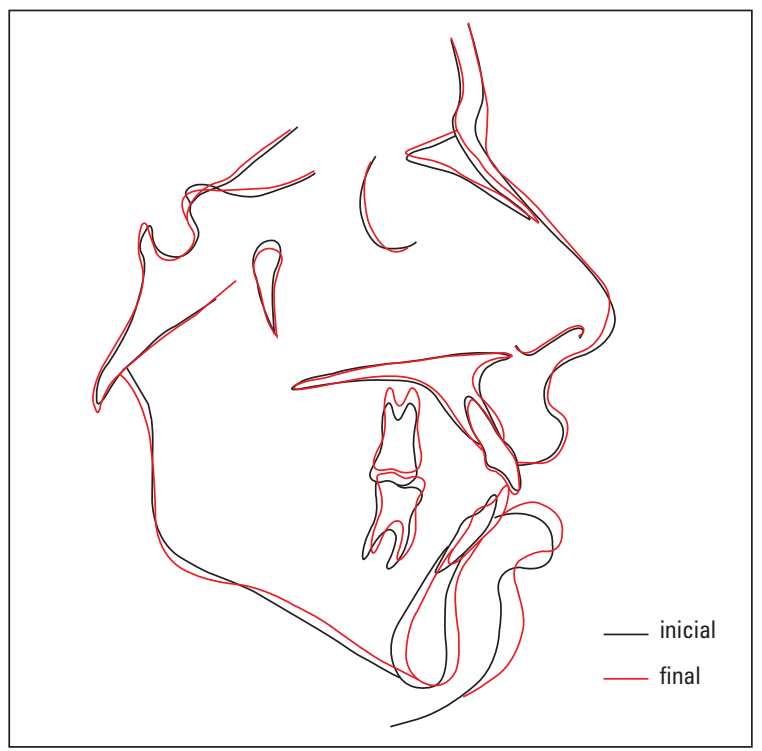

FIGURA 20 - Traçados cefalométricos inicial e final sobrepostos, mostrando a intrusão dos molares superiores e conseqüente giro da mandíbula no sentido anti-horário. duro e mole. Uma grande variedade desse problema pode ser tratada por essa técnica, evitando cirurgias ortognáticas ou mesmo diminuindo a complexidade do tratamento de certas condições.

Enviado em: junho de 2008 Revisado e aceito: julho de 2008 


\title{
Miniplates allow efficient and effective treatment of anterior open bites
}

\begin{abstract}
Introduction: The treatment of facial deformities and malocclusions, such as anterior open bite, was one of the first applications of miniplates for orthodontic anchorage. The use of this treatment system reduces the number of patients referred to orthognathic surgery and simplifies many problems. This approach applies intrusive forces to posterior teeth, and the mandible undergoes counterclockwise rotation, which decreases lower facial height and advances the projection of hard and soft tissue pogonions. Objective: This study describes the principles of orthodontic mechanics in the correction of anterior open bite and illustrates these principles with a series of cases.
\end{abstract}

Key words: Open bite. Orthodontics anchorage procedures. Mini-plates. Orthodontics.

\section{REFERÊNCIAS}

1. CHEN, C. H.; HSIEH, C. H.; TSENG, Y. C.; HUANG, I. Y.; SHEN, Y. S.; CHEN, C. M. The use of miniplate osteosynthesis for skeletal anchorage. Plast. Reconstr. Surg., Hagerstown, v. 120, no. 1, p. 232-235, 2007.

2. CHEN, Y. J.; CHANG, H. H.; HUANG, C. Y.; HUNG, C. Y.; LAI, E. H. H.; YAO, C. C. J. A retrospective analysis of the failure rate of the three different orthodontic skeletal anchorage systems. Clin. Oral Implants Res., Copenhagen, v. 18, no. 6, p. 768-775, 2007.

3. CHENG, S. J.; TSENG, I. Y.; LEE, J. J.; KOK, S. H. A prospective study of the risk factors associated with failure of mini-implants used for orthodontic anchorage. Int. J. Oral

Maxillofac. Implants, Lombard, v. 19, no. 1, p. 100-106, 2004.

4. CHIN, M. Y. H.; SANDHAM, A.; VRIES, J.; VANDER MEI, H. C.; BUSSCHER, H. J. Biofilm formation on surface characterized micro-implants for skeletal anchorage in Orthodontics. Biomaterials, Oxford, v. 28, no. 11, p. 2032-2040, 2007.

5. CHOI, B. H.; ZHU, S. J.; KIM, J. H. A clinical evaluation of titanium miniplates as anchors for orthodontic treatment. Am. J. Orthod. Dentofacial Orthop., St. Louis, v. 128, no. 3, p. 382-384, 2005.

6. CHUNG, K. R.; KIM, S. H.; MO, S. S.; KOK, Y. A.; KANG, S. G. Severe class II division 1 malocclusion treated by orthodontic miniplate with tube. Prog. Orthod., Berlin, v. 6, no. 2, p. 72-186, 2005

7. CHUNG, K. R.; KIM, Y. S.; LINTON, J. L.; LEE, Y. J. The miniplate with tube for skeletal anchorage. J. Clin. Orthod., Boulder, v. 36, no. 7, p. 407-412, 2002

8. ERVERDI, N.; ASCAR, A. Zygomatic anchorage for en masse retraction in the treatment of severe Class II division 1. Angle Orthod., Appleton, v. 75, no. 3, p. 483-490, 2005.

9. ERVERDI, N.; KELES, A.; NANDA, R. The use of skeletal anchorage in open bite treatment: a cephalometric evaluation. Angle Orthod., Appleton, v. 74, no. 3, p. 381-390, 2004.

10. FABER, J. Ancoragem esquelética com miniplacas. In: LIMA FILHO, R. M. A.; BOLOGNESE, A. M. Ortodontia: arte e ciência. Maringá: Dental Press, 2007. p. 449-473.

11. FABER, J.; BERTO, P. M.; ANCHIETA, M.; SALLES, F. Tratamento de mordida aberta anterior com ancoragem em miniplacas de titânio. Rev. Dental Press Estét., Maringá, v. 1, n. 1, p. $87-100,2004$

12. FABER, J.; VELASQUE, F. Titanium miniplate as anchorage to close a premolar space by means of mesial movement of maxillary molars. Am. J. Orthod. Dentofacial Orthop., St. Louis, 2008. No prelo.

13. JENNER, J. D.; FITZPATRICK, B. N. Skeletal anchorage utilizing bone plates. Aust. Orthod. J., Brisbane, v. 9, no. 2, p. 231-233, 1985.
14. KURODA, S.; KATAYAMA, A.; TAKANO-YAMAMOTO, T. Severe anterior open bite case treated using titanium screw anchorage. Angle Orthod., Appleton, v. 74, no. 4, p. 558-567, 2004.

15. KURODA, S.: SUGAWARA, Y.: DEGUCHI, T.: KYUNG, H. M.; YAMAMOTO, T. T. Clinical use of miniscrew implants as orthodontic anchorage: success rates and postoperative discomfort. Am. J. Orthod. Dentofacial Orthop., St. Louis, v. 131, no. 1, p. 9-15, 2007

16. KURODA, S.; YAMADA, K.; DEGUCHI, T.; HASHIMOTO, T.; KYUNG, H. M.; YAMAMOTO, T. T. Root proximity is a major factor for screw failure in orthodontic anchorage. Am. J. Orthod. Dentofacial Orthop., St. Louis, v. 131, no. 4, p. S68-S73, 2007. Supplement.

17. LONDA, G. The anchorage quality of titanium microplates with short microscrews for orthodontic anchorage applications. J. Orofac. Orthop., München, v. 66, p. 67-77, 2005.

18. SHERWOOD, K.; BURSH, J. Skeletally based miniplates supported orthodontic anchorage. J. Oral Maxillofac. Surg. Philadelphia, v. 63, no. 2, p. 279-284, 2005.

19. SHERWOOD, K. H.; BURCH, J. G.; THOMPSON, W. J. Closing anterior open bites by intruding molars with titanium miniplate anchorage. Am. J. Orthod. Dentofacial Orthop., St. Louis, v. 122, no. 6, p. 593-600, 2002.

20. SHERWOOD, K. H.; BURCH, J. G.; THOMPSON, W. J. Intrusion of supererupted molars with titanium miniplate anchorage. Angle Orthod., Appleton, v. 73, no. 5, p. 597-601, 2003.

21. SUGAWARA, J.; DAIMARUYA, T.; UMEMORI, M.; NAGASAKA, H.; TAKAHASHI, I.; KAWAMURA, H. et al. Distal movement of mandibular molars in adult patients with skeletal anchorage system. Am. J. Orthod. Dentofacial Orthop., St. Louis, v. 125, no. 2, p. 130-138, 2004.

22. SUGAWARA, J.; KANZAKI, R.; TAKAHASHI, I.; NAGASAKA, H.; NANDA, R. Distal movement of maxillary molars in nongrowing patients with the skeletal anchorage system. Am. J. Orthod. Dentofacial Orthop., St. Louis, v. 129, no. 6, p. 723-733, 2006

23. SUGAWARA, J.; NISHIMURA, M. Minibone plates: the skeletal anchorage system. Semin. Orthod., Philadelphia, v. 11, no. 1, p. 47-56, 2005.

24. UMEMORI, M.; SUGAWARA, J.; MITANI, H.; NAGASAKA, H.; KAWAMURA, H. Skeletal anchorage system for open-bite correction. Am. J. Orthod. Dentofacial Orthop., St. Louis, v. 115, no. 2, p. 166-174, 1999.

Endereço para correspondência

Jorge Faber

SCN Brasília Shopping, SL 408

CEP: 70.715-900 - Brasília/DF

E-mail: jorgefaber@terra.com.br 